\title{
Using DC-DC Converters as Active Harmonic Suppression Device for More Electric Aircraft Applications
}

\author{
Cheng Wang, Tao Yang, Senior Member, IEEE, Habibu Hussaini, and Serhiy Bozhko, \\ Senior Member, IEEE
}

\begin{abstract}
Harmonics generated from power electronic converters will impose significant power quality challenges to the electric grid onboard future aircraft. In this paper, we propose an innovative modulation scheme that enables using a buck-boost DC-DC converter as a harmonic absorber. To demonstrate the effectiveness of the proposed method, a hybrid power generation system involving a high-speed electrical generator and a high voltage battery is introduced. The electrical generator is connected to a DC bus through an AC-DC converter and the battery to the DC bus with a DC-DC converter. For the studied hybrid power generation system, it is identified that the first carrier frequency side-band harmonic $\left(f_{c}-3 f_{0}\right)$ from the AC-DC converter is most relevant and is targeted for cancellation. For the control of the DC-DC converter, a new modulation technique, called equal-gate-width (EGW) modulation is proposed. It allows active control of the magnitude and phase angle of some specific harmonic components from a DC-DC converter. By properly tuning the phase angle and amplitude, the controlled harmonics can thus be used to cancel harmonics from other converters on a common DC bus. Without losing generality, the paper focuses on the development of this specific harmonic cancellation scheme and the effectiveness of our proposed methods has been demonstrated using experimental results.
\end{abstract}

Index Terms- harmonics cancellation, more-electric aircraft, power electronics, DC-DC converter power system

\section{INTRODUCTION}

$\mathrm{M}$ ORE electric aircraft (MEA) concept has become one of the major trends in aerospace development due to decreased fuel consumption, low maintenance cost, etc [1][2]. Single DC-bus power systems have attracted significant interest due to their benefits including low cable usage, convenient integration of sources, and high redundancy ability [3]. A hybrid DC power generation system for the MEA electrical power system (EPS) used for this study is shown in Fig. 1. The

This work was supported by the Clean Sky 2 Joint Undertaking under Grant 807081. (Corresponding author: Tao Yang.) The author Cheng Wang also thanks the stipend funding from China Scholarship Council (CSC).

C. Wang, T. Yang, H. Hussaini, S. Bozhko are with the Power Electronics, Machines and Control Group, The University of Nottingham, Nottingham NG7 2RD, U.K. (emails: cheng.wang@nottingham.ac.uk; tao.yang@nottingham.ac.uk; habibu.hussaini@nottingham.ac.uk; serhiy.bozhko@nottingham.ac.uk). power is mainly supplied by a permanent magnet synchronous generator (PMSG), which extracts power from the engine highspeed shaft. An energy storage system is also integrated. To achieve a flexible power flow, a buck-boost bi-directional DCDC converter is implemented to control the battery operation in both charging and discharging modes. The battery is mainly to provide a flexible power flow, and thus the system performance (i.e., efficiency, fault tolerance) can potentially be improved.

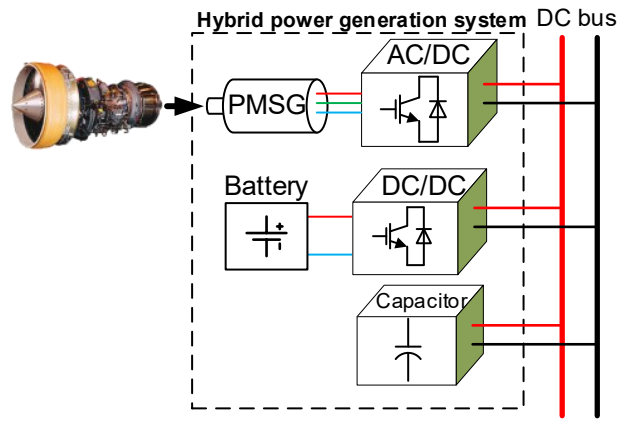

Fig. 1. Hybrid power generation system on MEA.

The penetration of power electronics has put significant challenges on electric grid power quality. Specifically, the power quality of the aircraft electrical system is required to meet aerospace standards such as DO-160E [4] and MIL-STD$704 \mathrm{~F}$ [5]. A capacitor bank can be used to filter out highfrequency fluctuated currents and flatten the DC-bus voltage. However, the capacitor is always bulky and expensive. With reduced harmonics, reduced size and weight of the dc-bus capacitor can be achieved. This, in return, gives the system a higher efficiency, reduced mass and lower fuel consumption. Furthermore, with lower harmonics, the capacitor lifetime is extended as well [6].

There are numerous methods proposed to minimize current ripples across capacitors [7]-[10]. However, the control bandwidth of those methods is mostly below the switching frequency. This means that current harmonics due to the switching behaviour of converters are filtered out in the control loop. This paper aims to fill this gap and propose a simple method that can suppress the switching harmonics of the current flowing into the capacitor.

Many researchers have studied this issue in recent years. Among them, active suppression of harmonics across capacitors has received attention because of its flexibility. Related studies have been reported in a few publications. 
Adding additional circuits is the most direct method [11]-[14]. In those cases, additional switching devices were added to the system and harmonics on capacitors were effectively reduced with an adjustable switching operation of the extra switches. However, this method requires extra elements and thus increases the cost and complexity of the electrical systems. In $[15][16]$, the authors investigated harmonic suppression in the second switching frequency for the DC power system. However, there is no DC-DC converter involved and harmonics with lower order such as the first-band harmonics are not considered. Since the DC-DC converter is foreseen to be one essential element connected to high voltage DC (HVDC) buses on future aircraft, it is critical to include such devices in the MEA electrical systems.

This paper aims to fill the gap and use a buck-boost DC-DC converter as an active harmonic sink for the DC power system. We propose a new modulation scheme for such a converter that can actively change the magnitudes and phase angles of its harmonic components. Some specific harmonics on the DC-bus thus can be eliminated by tuning the magnitude and phase angle of this specific harmonic component from the DC-DC converter. In this paper, although we focus on some specific harmonic component, the proposed method can essentially be used to suppress any harmonic component of interest by simply changing the phase angle and frequency of the carrier signal as well as the position of 'on' switching states of power devices in one cycle within the DC-DC converter.

The work presented in this paper is continuous research from our recent publication [15], where a harmonic cancellation scheme has been proposed for multiple AC-DC converters supplying HVDC bus. In this paper, we extend this work and consider a DC bus supplied by both AC-DC and DC-DC converters. This paper is organized in the following manner. Section II presents a harmonic analysis of the two-level AC-DC converter. A harmonic in the first band switching frequency is selected for suppression based on a mathematical comparison. To absorb this harmonic using a DC-DC converter, Section III illustrates a new PWM method of the DC-DC converter for adjusting magnitudes of harmonics. Section IV proposes a harmonic suppression method based on discussion from the previous sections, and Section $\mathrm{V}$ presents the experimental results. Section VI concludes this paper.

\section{HARMONIC ANALYSIS OF TWO-LEVEL AC-DC CONVERTER}

In the system shown in Fig. 1, the PMSG supplies electrical power to the HVDC bus through an AC-DC converter, with details shown in Fig. 2a. To develop a harmonic cancellation scheme for the HVDC bus, it is essential to derive the mathematical model of its harmonics before the capacitor. In this study, a standard two-level AC-DC converter is considered for AC-DC conversion because it is known as the most widely used rectifier for PMSG based power generation systems. The asymmetrical sampling PWM adjusts the duty cycle twice in one switching cycle, which gives a better voltage output performance compared to the symmetric sampling. Hence, it is assumed that the common asymmetrical regular sampling PWM is implemented in the AC-DC converter, as shown in Fig. 2b. Due to the converter switching actions, the DC-link current $i_{d c}{ }^{[g]}$ will contain harmonics, as shown in Fig. 2c with its spectrum. It can be noticed that significant components of the current harmonics are observed in $f_{c} \pm 3 f_{0}$ and $2 f_{c}$. Here, $f_{c}$ is the switching frequency and $f_{0}$ is the fundamental frequency of the PMSG. Harmonics in higher frequencies are not considered because of their lower impact on the DC-bus.

The scenario of harmonic spectrum distribution has been analyzed in [17]. In this section, a simplified mathematical model of three harmonics $\left(f_{c} \pm 3 f_{0}\right.$ and $\left.2 f_{c}\right)$ of interest will be studied in more details. Based on the mathematical models, reasons for suppressing current harmonic components in the first switching band will be given.

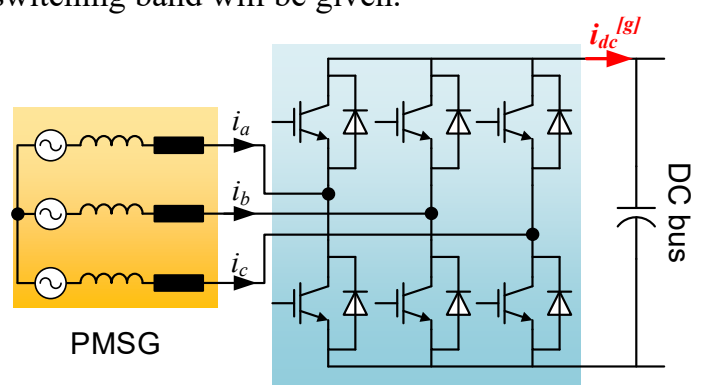

(a)

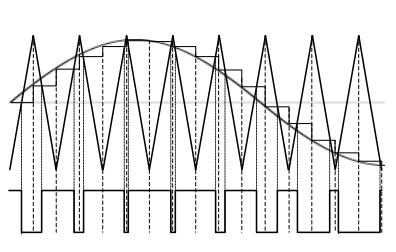

(b)

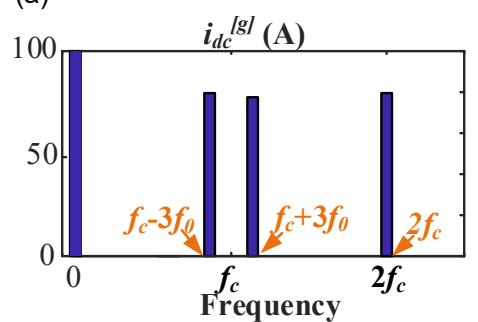

(c)
Fig. 2. Two-level three-phase converter. a) PMSG and 2-level converter. b) Asymmetric regular sampling PWM. c) Spectrum of $i_{d c}$.

\section{A. Mathematical analysis of DC-bus harmonic based on Double-Fourier method}

The Double Fourier method is commonly used to study the harmonics of PWM operation [17]. Some analysis has been investigated in [15], which will be briefly reviewed here.

Assuming the current on the AC side is ideally sinusoidal for a two-level converter, the AC side currents can be written as in (1).

$$
i_{a c}^{[k]}(t)=I_{a c} \cos \left(2 \pi f_{0} t+\beta+\frac{2 k \pi}{3}\right)
$$

where $I_{a c}$ is the amplitude of the fundamental component of $\mathrm{AC}$ current, $f_{0}$ is the fundamental frequency, $\beta$ is the angle between phase current and its $\mathrm{AC}$ side voltage, $k=0,1$ and 2 represent phase $\mathrm{A}, \mathrm{B}$ and $\mathrm{C}$ respectively.

Assuming the positive current on the DC bus $\left(i_{d c}\right)$ is from the converter to the dc-link capacitor, as shown in Fig. 2. The switching function for each phase leg can be expressed as in (2).

$$
\begin{aligned}
& s f^{[k]}(t)=K_{0,1} \cos \left(2 \pi f_{0} t+\beta+\alpha+\frac{2 k \pi}{3}\right) \\
& +\sum_{m=1}^{\infty} \sum_{n=-\infty}^{\infty} K_{m, n} \cos \left[\begin{array}{l}
m\left(2 \pi f_{c} t+\theta_{c}^{[k]}\right) \\
+n\left(2 \pi f_{0} t+\beta+\alpha+\frac{2 k \pi}{3}\right)
\end{array}\right]
\end{aligned}
$$


where $f_{c}$ is the switching frequency, $\theta_{c}^{[k]}$ is the phase angle of the triangular carrier signal for each leg, $\alpha$ is the phase angle between the $\mathrm{AC}$ fundamental current and the AC-side converter voltage (i.e. power factor angle), $K_{m, n}$ is the harmonic amplitude using the Bessel function of the first kind. Based on double Fourier analysis [17], $K_{m, n}$ can be expressed as

$$
K_{m, n}=\frac{1}{q_{m, n}} J_{n}\left(q_{m, n} M\right) \sin \left[(m+n) \frac{\pi}{2}\right]
$$

where

$$
q_{m, n}=\left(m+n \frac{f_{0}}{f_{c}}\right) \frac{\pi}{2}
$$

In (3), $J_{n}()$ is the Bessel function of the first kind. $m$ and $n$ are the orders of switching harmonic and its side bands respectively. For instance, when $m=1$ and $n=3, K_{m, n}$ means the magnitude of harmonic with a frequency of $f_{c}+3 f_{0}$. Using (1) (4), the DC-bus harmonic currents generated from one phase leg can be derived as

$$
\left.\begin{array}{l}
i_{d c}^{[k]}(t)=i_{a c}^{[k]}(t) s f^{[k]}(t) \\
=\frac{I_{a c}}{2} K_{0,1}\left[\cos \left(4 \pi f_{0} t+2 \beta+\alpha+\frac{4 k \pi}{3}\right)+\cos \alpha\right] \\
+\frac{I_{a c}}{2} \sum_{m=1}^{\infty} \sum_{n=-\infty}^{\infty} K_{m, n}\left\{\begin{array}{l}
\cos \left[2 \pi\left(m f_{c}+(n+1) f_{0}\right) t+\sigma_{m, n}^{[k]}\right] \\
+\cos \left[2 \pi\left(m f_{c}+(n-1) f_{0}\right) t+\varphi_{m, n}^{[k]}\right.
\end{array}\right]
\end{array}\right\}
$$

where $\sigma_{m, n}^{[k]}$ and $\varphi_{m, n}^{[k]}$ are the phase angles of each component, which are

$$
\begin{aligned}
& \sigma_{m, n}^{[k]}=m \theta_{c}^{[k]}+(n+1)\left(\beta+\frac{2 k \pi}{3}\right)+n \alpha \\
& \varphi_{m, n}^{[k]}=m \theta_{c}^{[k]}+(n-1)\left(\beta+\frac{2 k \pi}{3}\right)+n \alpha
\end{aligned}
$$

Extracted from (5), the DC-link current harmonics in a specific frequency $\left(i f_{c}+j f_{0}\right)$ should be expressed as a sum of components from the three legs as

$$
\begin{aligned}
& i_{d c, i, j}^{[g]}(t)=\frac{I_{a c}}{2} K_{i, j-1} \sum_{k=0}^{2} \cos \left[2 \pi\left(i f_{c}+j f_{0}\right) t+\sigma_{i, j-1}^{[k]}\right] \\
& +\frac{I_{a c}}{2} K_{i, j+1} \sum_{k=0}^{2} \cos \left[2 \pi\left(i f_{c}+j f_{0}\right) t+\varphi_{i, j+1}^{[k]}\right]
\end{aligned}
$$

where $i$ and $j$ represent the switching and band side orders of DC-bus current harmonics respectively. For instance, substituting $i=1$ and $j=3$ into (8) gives the expression of harmonic in the frequency of $f_{c}+3 f_{0}$. Here we use a superscript [g] indicating this harmonic is associated with the generator connected to the AC-DC converter and is to differentiate it from the DC-DC converter which will be discussed in the later sections.

\section{B. Harmonics on $f_{c \pm 3 f_{0}}$}

As shown in Fig. 2c, significant harmonics appear in the frequencies of both $f_{c}-3 f_{0}$ and $f_{c}+3 f_{0}$. Furthermore, along the whole spectrum, their magnitude cannot be ignored.

This subsection will analyze the harmonic in $f_{c}-3 f_{0}$ firstly. Considering no phase shift on carrier signals among three legs, i.e., $\theta_{c}^{[1]}=\theta_{c}^{[2]}=\theta_{c}{ }^{[3]}=\theta_{c}$, substituting $i=1$ and $j=-3$ into (8) gives

$$
\begin{aligned}
& i_{d c, 1,-3}^{[g]}(t)=\frac{3 I_{a c}}{2} K_{1,-4} \cos \left[2 \pi\left(f_{c}-3 f_{0}\right) t+\sigma_{1,-4}\right] \\
& +\frac{3 I_{a c}}{2} K_{1,-2} \cos \left[2 \pi\left(f_{c}-3 f_{0}\right) t+\varphi_{1,-2}\right]
\end{aligned}
$$

For the coefficient $K_{l,-4}$ and $K_{l,-2}$, we have

$$
\begin{gathered}
K_{1,-4}=\frac{2}{\left(1-4 \frac{f_{0}}{f_{c}}\right) \pi} J_{4}\left(\frac{\pi}{2}\left(1-4 \frac{f_{0}}{f_{c}}\right) M\right) \\
K_{1,-2}=-\frac{2}{\left(1-2 \frac{f_{0}}{f_{c}}\right) \pi} J_{2}\left(\frac{\pi}{2}\left(1-2 \frac{f_{0}}{f_{c}}\right) M\right)
\end{gathered}
$$

Assuming that $f_{c}>>f_{0}$ (in typical cases, $f_{c}$ is at least 20 times the frequency of $f_{0}$ ), the term $f_{0} / f_{c}$ can be neglected as it is approximately equal to 0 . Then, (9) can be approximated as expressed in (12).

$$
\begin{aligned}
& i_{d c, 1,-3}^{[g]}(t) \approx \frac{3 I_{a c}}{\pi} J_{4}\left(\frac{\pi}{2} M\right) \cos \left[2 \pi\left(f_{c}-3 f_{0}\right) t+\sigma_{1,-4}\right] \\
& -\frac{3 I_{a c}}{\pi} J_{2}\left(\frac{\pi}{2} M\right) \cos \left[2 \pi\left(f_{c}-3 f_{0}\right) t+\varphi_{1,-2}\right]
\end{aligned}
$$

Comparing the two terms in (12), their magnitudes have different Bessel functions and are given in (13).

$$
\frac{3 I_{a c}}{\pi} J_{4}\left(\frac{\pi}{2} M\right) \text { and }-\frac{3 I_{a c}}{\pi} J_{2}\left(\frac{\pi}{2} M\right)
$$

In (13), the modulation index $(M)$ is always less than 1 , because of the limited output voltage of the AC-DC converter. A comparison between the two Bessel function terms when $M<1$ is shown in Fig. 3. It can be seen that $J_{4}(\pi M / 2)$ is almost zero, and $J_{2}(\pi M / 2)$ is more than 20 times higher.

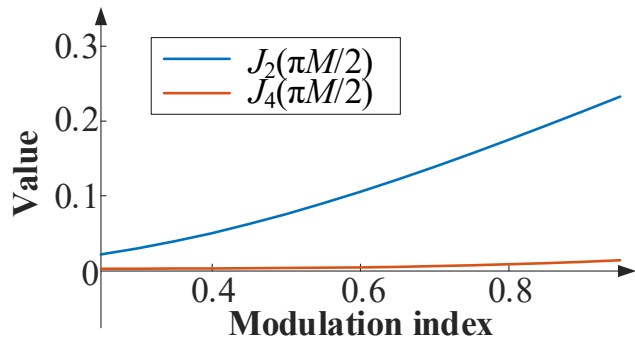

Fig. 3. Comparison between $J_{2}(\pi M / 2)$ and $J_{4}(\pi M / 2)$ with increased modulation index.

Hence, the first term is neglectable in (12). Therefore, the expression in (12) becomes as in (14).

$$
i_{d c, 1,-3}^{[g]}(t) \approx \frac{3 I_{a c}}{\pi} J_{2}\left(\frac{\pi}{2} M\right) \cos \left[2 \pi\left(f_{c}-3 f_{0}\right) t+\varphi_{1,-2}+\pi\right]
$$

With (14), the magnitude of the $f_{c}-3 f_{0}$ harmonic is convenient for a controller to calculate. There, $M$ will be a fixed value if the PMSG works under flux-weakening operation (which is a normal case for aerospace application). $I_{a c}$ is measured by current sensors and is expressed as

$$
I_{a c}=\sqrt{i_{d}^{2}+i_{q}^{2}}
$$

where $i_{d}$ and $i_{q}$ are the $d$ - and $q$-axis currents of the PMSG. Apart from magnitude, the phase angle of the component in (14) 
can be derived from (7) which gives the expression as

$$
\varphi_{1,-2}+\pi=\theta_{c}-2(\alpha+\beta)-\beta+\pi
$$

where $\beta$ is the angle between the phase current and its AC side voltage and $\alpha$ is the power factor angle. Both of them can be achieved from voltages and currents in $d q$-frame, which are

$$
\begin{gathered}
\alpha+\beta=\operatorname{atan} 2\left(v_{q}, v_{d}\right) \\
\beta=\operatorname{atan} 2\left(i_{q}, i_{d}\right)
\end{gathered}
$$

Here, the function $\operatorname{atan} 2(y, x)$ gives the angle of the complex value $(x+i y)$. Therefore, the magnitude $\left(I_{d c, 1,-3}{ }^{[g]}\right)$ and phase angle $\left(\theta_{d c, 1,-3}{ }^{[g]}\right)$ of the harmonic in $f_{c}-3 f_{0}$ can be summarized from (14) to (18) as

$$
\begin{gathered}
I_{d c, 1,-3}^{[g]} \approx \frac{3 \sqrt{i_{d}^{2}+i_{q}^{2}}}{\pi} J_{2}\left(\frac{\pi}{2} M\right) \\
\theta_{d c, 1,-3}^{[g]} \approx \theta_{c}-2 \operatorname{atan} 2\left(v_{q}, v_{d}\right)-\operatorname{atan} 2\left(i_{q}, i_{d}\right)+\pi
\end{gathered}
$$

Following the same process, the magnitude and phase angle of the harmonic component in $f_{c}+3 f_{0}$ can be calculated and simplified as

$$
\begin{gathered}
I_{d c, 1,3}^{[g]} \approx \frac{3 \sqrt{i_{d}^{2}+i_{q}^{2}}}{\pi} J_{2}\left(\frac{\pi}{2} M\right) \\
\theta_{d c, 1,3}^{[g]} \approx \theta_{c}+2 \operatorname{atan} 2\left(v_{q}, v_{d}\right)+\operatorname{atan} 2\left(i_{q}, i_{d}\right)+\pi
\end{gathered}
$$

From (19) and (21), it is important to notice that the simplified magnitudes of these two components of frequencies $\left(f_{c}-3 f_{0}\right.$ and $f_{c}+3 f_{0}$ ) are essentially the same. A comparison between the magnitudes of the simplified model and the original model is given in Fig. 4a. The error is always less than $3 \mathrm{~A}$, which is less than $10 \%$ of the original model, as shown in Fig. $4 \mathrm{~b}$. Therefore, the simplified model can be adopted and used for the harmonic suppression method.

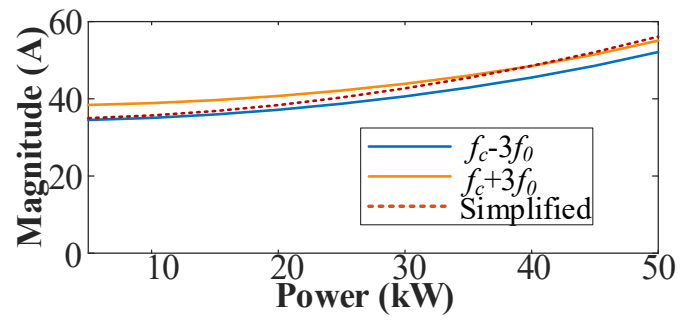

(a)

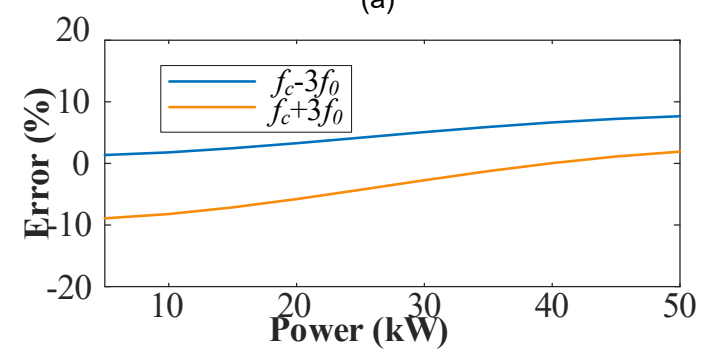

(b)

Fig. 4. Comparison between magnitudes of the simplified and original model on $f_{c}-3 f_{0}$ and $f_{c}+3 f_{0}$. a) Magnitudes. b) Errors.

We also found that the proposed simplified models match well with the symmetric sampling PWM when assuming $f_{c}>>$ $f_{0}$. However, this is not the main contribution of this paper and will not be illustrated in detail.

\section{Component selection for suppression}

As shown in Fig. 2c, another significant harmonic exists in $2 f_{c}$. In [14], the magnitude of this component is analyzed and simplified as

$$
I_{d c, 2,0}^{[g]} \approx \frac{3 I_{a c} \cos \alpha}{\pi} J_{1}(\pi M)
$$

Comparing the simplified magnitudes of harmonic in the first band $\left(f_{c} \pm 3 f_{0}\right)$ and second $\left(2 f_{c}\right)$ switching frequencies and dividing (23) by (19) or (21) gives

$$
\frac{I_{d c, 2}^{[g]}}{I_{d c, 1}^{[g]}} \approx \frac{I_{d c, 2,0}^{[g]}}{I_{d c, 1,-3}^{[g]}} \approx \frac{I_{d c, 2,0}^{[g]}}{I_{d c, 1,3}^{[g]}} \approx\left|\frac{J_{1}(\pi M)}{J_{2}\left(\frac{\pi}{2} M\right)} \cos \alpha\right|
$$

where $I_{d c, 2}{ }^{[g]}$ is the simplified magnitude of harmonics in $2 f_{c}$. $I_{d c, l} I^{[g]}$ is the simplified magnitude of harmonics in $f_{c} \pm 3 f_{0}$.

Due to the cosine value is always less than 1 , it can be obtained from (24) that

$$
\frac{I_{d c, 2}^{[g]}}{I_{d c, 1}^{[g]}} \approx\left|\frac{J_{1}(\pi M)}{J_{2}(\pi M / 2)} \cos \alpha\right|<\left|\frac{J_{1}(\pi M)}{J_{2}(\pi M / 2)}\right|
$$

Considering the fact that the PMSGs always work under flux-weakening control in MEA because of the wide shaft speed range of the engine [21], the modulation index $(M)$ will always be higher than 0.9 for the PMSG connected to the AC-DC converter. Therefore, the maximum value in (25) which is $\left|J_{l}(\pi M) / J_{2}(\pi M / 2)\right|$ is as shown in Fig. 5.

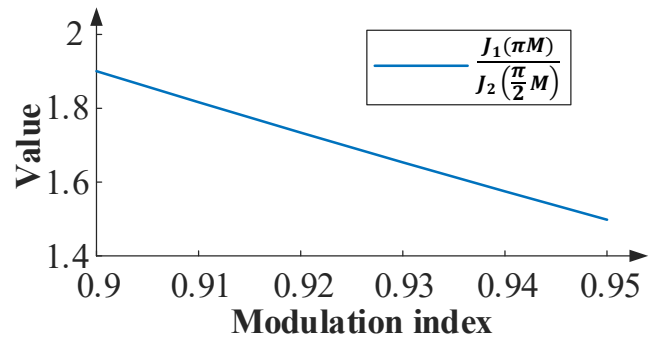

Fig. 5. Variation of $J_{1}(\pi M) / J_{2}(\pi M / 2)$ with an increase in modulation index.

As shown in Fig. 5, the ratio between $I_{d c, 2}$ and $I_{d c, 1}$ is always less than 2 when the modulation index is higher than 0.9. Hence, we obtain the expression in (26).

$$
\frac{I_{d c, 2}^{[g]}}{I_{d c, 1}^{[g]}}<\left|\frac{J_{1}(\pi M)}{J_{2}\left(\frac{\pi}{2} M\right)}\right|<2
$$

To minimize the voltage ripple on the DC capacitor, the total capacitor harmonics of switching frequencies should be analyzed as follows:

$$
I_{h f}=\sqrt{\sum_{k=1}^{\infty}\left(\frac{I_{k}}{f_{k}}\right)^{2}}
$$

where $I_{h f}$ is total harmonics on the DC capacitor, $f_{k}$ is the frequency of the $k$ th order harmonic, and $I_{k}$ is the magnitude of the summed $k$ th order harmonics.

According to (26), we have 


$$
\left(\frac{I_{d c, 2}^{[g]}}{2 f_{c}}\right)^{2}<\left(\frac{I_{d c, 1}^{[g]}}{f_{c}}\right)^{2}<\left(\frac{I_{d c, 1}^{[g]}}{f_{c}-3 f_{0}}\right)^{2}
$$

Meanwhile,

$$
\left(\frac{I_{d c, 1}^{[g]}}{f_{c}+3 f_{0}}\right)^{2}<\left(\frac{I_{d c, 1}^{[g]}}{f_{c}-3 f_{0}}\right)^{2}
$$

From (28) and (29), it can be seen that the component in $f_{c^{-}}$ $3 f_{0}$ contributes more to the DC-link fluctuation compared to that in $2 f_{c}$ and $f_{c}+3 f_{0}$. Hence, this paper focuses more on the harmonic suppression in the frequency of $f_{c}-3 f_{0}$ by using a DCDC converter, as discussed in the following section.

\section{HARMONIC ANALYSIS OF DC-DC CONVERTERS}

This section will discuss the harmonics generated from a DCDC converter to suppress the $f_{c}$ - $3 f_{0}$ harmonic generated from the AC-DC converter, as explained in Section II. In MEA application, reliability is of high concern. Thus, a buck-boost DC-DC converter is selected in this paper because of its simple structure and high reliability. . As shown in Fig. 6, the bidirectional buck-boost DC-DC converter consists of two power switches $\left(S_{1}\right.$ and $\left.S_{2}\right)$ with anti-parallel diodes and a filtering inductor $L_{b}$. The port on the left is connected to a battery with a voltage $V_{b}$, and the port on the right is connected to a DC-bus with voltage $V_{d c}$. This DC-DC converter allows the battery to work under both charging and discharging modes. However, in this paper, we focus on the discharging mode only.

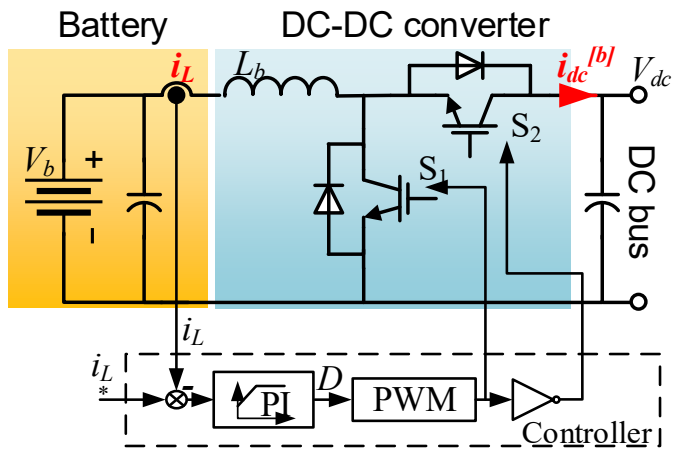

Fig. 6. Bidirectional buck-boost converter.

\section{A. Conventional DC-DC converter control and PWM operation}

Within the hybrid electric power generation centre, a secondary level supervision unit is used to provide the reference power (thus defines inductor current $i_{L}$ ) to the DC-DC converter local control. A typical control diagram of a DC-DC converter is shown in Fig. 6. Average current control is used here, and the modeling and operation of such control has been well studied already [23]. PWM signals are generated to control switches $\mathrm{S}_{1}$ and $S_{2}$. The switching behaviour of these switches causes the DC-link current ripples.

The conventional PWM of the buck-boost DC-DC converter is shown in Fig. 7. It can be seen that switching signals are generated by comparing the duty cycle reference and carrier signal. The carrier signal is a triangle waveform. The period of a carrier signal is defined as $T_{c}^{[b]}$. The average DC current $i_{d c}^{[b]}$ and its contained harmonics are dependent on the power reference (and thus $i_{L}$ ). Similar to AC-DC converters, the $i_{d c}^{[b]}$ harmonics phase angle can be controlled by shifting the phase angle of the carrier signal. However, since the power reference is given by an upper-level controller (at the secondary level) and dependent on load requirements within the hybrid power generation centre, the power reference (and thus $I_{L}$ value) is thus an input value and cannot be controlled by a local controller of a DC-DC converter. Therefore, for the $i_{d c}^{[b]}$ harmonics, although their phase angles are controllable, this is not the case for their magnitudes for a local controller. This makes the conventional modulation technique not feasible to be used to cancel harmonics from AC-DC converters, as the adjustable magnitudes and phase angles of harmonics are essential. Thus, a new modulation technique is required and will be discussed.

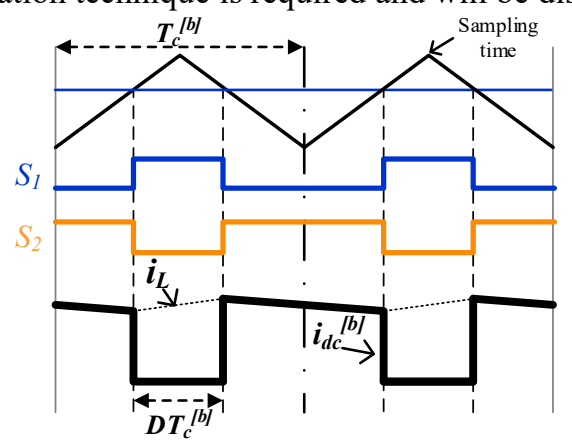

Fig. 7. Conventional PWM strategy.

In this paper, the DC-DC converter is to control the battery current $i_{L}$ to its reference $i_{L}{ }^{*}$. Apart from the conventional PWM strategy, the current control can also be achieved by hysteresis control or peak current control. However, for the hysteresis control, the switching frequency is not fixed and thus is not suitable for active suppression of the specific harmonic component. For the peak current control, it controls the peak current of $i_{L}$ with a fixed switching frequency. The current waveform of $i_{c a p}$ is similar to the conventional PWM case under the steady-state. Therefore, it will not be discussed in detail.

\section{B. Equal-Gate-Width PWM}

In this section, a new modulation scheme is developed to enable active control of the harmonic magnitudes as well as their phase angles. The new PWM method is named as equalgate-width (EGW) PWM method and is shown in Fig. 8. There, one cycle time of a carrier signal is defined as $T^{[b]}$. The switch $\mathrm{S}_{1}$ turns on twice within one $T^{[b]}$ and each time is on for a period of $D T^{[b]} / 2$. Here $D$ is the duty cycle of the gate signal from the proportional-integral (PI) controller output. These two turn-on

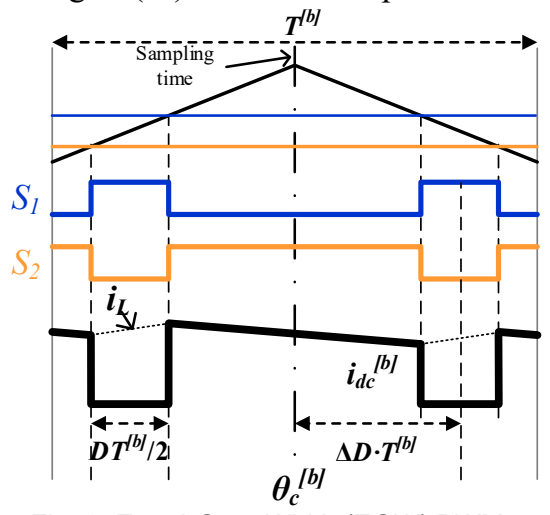

Fig. 8. Equal-Gate-Width (EGW) PWM. 
periods are also symmetrical from the half cycle $T^{[b]} / 2$. The offset referred to its centre is defined as $\Delta D \cdot T^{[b]}$. Since $\mathrm{S}_{1}$ switches on twice for one carrier signal cycle, the carrier signal of the proposed EGW can be with a doubled period compared with that of conventional PWM $\left(T^{[b]}=2 T_{c}^{[b]}\right)$ for the same switching frequency.

To simplify the analysis, the inductor current is assumed to be constant as $I_{L}$, and the converter works under continuous current mode. Then, the current flowing into the dc-bus capacitor, $i_{d c}^{[b]}$, is given as

$$
i_{d c}^{[b]}=\left\{\begin{array}{cc}
I_{L}, & -\frac{T^{[b]}}{2}<t<-\frac{(4 \Delta D+D) T^{[b]}}{4} \\
I_{L}, & -\frac{(4 \Delta D-D) T^{[b]}}{4}<t<\frac{(4 \Delta D-D) T^{[b]}}{4} \\
I_{L}, & \frac{(4 \Delta D+D) T^{[b]}}{4}<t<\frac{T^{[b]}}{2} \\
0, & \text { else }
\end{array}\right.
$$

Considering the symmetry and using Fourier expansion, the current $i_{d c}{ }^{[b]}$ can be expressed as

$$
i_{d c}^{[b]}=A_{0}+\sum_{k=1}^{\infty} A_{k} \cos \left(2 k \pi f_{c}^{[b]} t+k \theta_{c}^{[b]}\right)
$$

where

$$
f_{c}^{[b]}=\frac{1}{T^{[b]}}
$$

From (31), it can be seen that the phase angle of current $i_{d c}[b]$ harmonics are related to the carrier signal phase angle $\theta_{c}$. The Fourier coefficients in (31) are derived as

$$
\begin{gathered}
A_{0}=I_{L}(1-D) \\
A_{k(k \neq 0)}=2 f_{c}^{[b]} \int_{-\frac{1}{2 f_{c}^{[b]}}}^{\frac{1}{2 f_{c}^{[b]}}} i_{d c}^{[b]}(t) \cos \left(2 k \pi f_{c}^{[b]} t\right) d t \\
=-\frac{4 I_{L}}{k \pi} \sin \left(\frac{k \pi D}{2}\right) \cos 2 k \pi \Delta D
\end{gathered}
$$

From (34), it can be noticed that the magnitudes of harmonic components $A_{k}$ can be controlled with $\Delta D$. This is a very useful finding, as adjusting this variable will change the location of the turn-on pulse of $\mathrm{S}_{1}$ but have no impact on the duty cycle $D$ from the controller. Combining with (31), we can come to the conclusion that the proposed EGW PWM scheme has achieved active control of magnitudes and phase angle of current $i_{d c}^{[b]}$ harmonics.

The adjustable range of $\Delta D$ is limited by $D$ and defined as

$$
\frac{D}{4}<\Delta D<\frac{1}{2}-\frac{D}{4}
$$

This limitation is essentially because if $\Delta D$ exceeds the range of (35), the two gate signal pulses of $S_{1}$ in Fig.8 will overlap each other, as shown in Fig. 9.

Considering that the DC-DC converter works under steadystate boost operation, the duty cycle of the DC-DC converter is given as

$$
D=1-\frac{V_{b}}{V_{d c}}
$$

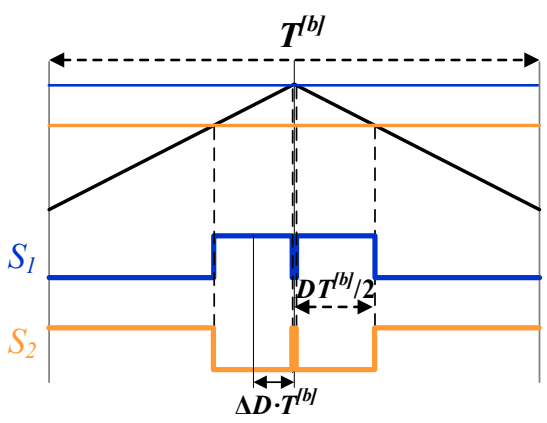

(a)

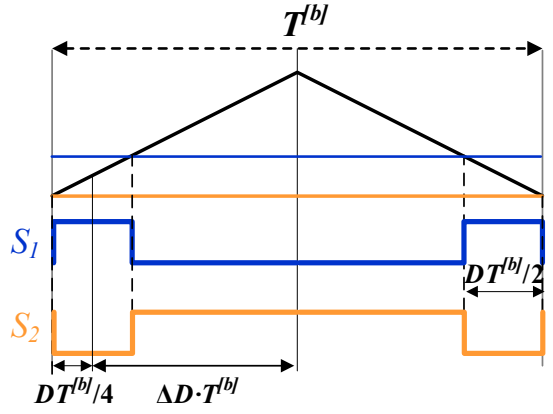

(b)

Fig. 9. EGW operation when the two gate signal pulses of $S_{1}$ are going to overlap each other. a) $\Delta D=D / 4$. b) $\Delta D=1 / 2-D / 4$.

Fig. 10 shows the amplitudes of the first and second-order switching harmonics of $i_{d c}^{[b]}\left(A_{1}\right.$ and $A_{2}$ ) for the DC-DC converter with the proposed EGW PWM scheme. There, we assumed the battery voltage is $200 \mathrm{~V}$ and the dc bus voltage to be $270 \mathrm{~V}$. The current $I_{L}$ is set to be at $50 \mathrm{~A}$. Harmonics higher than the second-order are not considered here due to their low impact on DC-link capacitors. From Fig. 10, it can be seen that the magnitudes of the first and second switching harmonic vary when $\Delta D$ changes. Since the harmonic component phase angle can be controlled by changing the carrier signal angle $\theta_{c}$, we can conclude that the proposed EGW has the potential to cancel harmonics from AC-DC converters on the DC bus. This will be discussed in more detail in the next section.

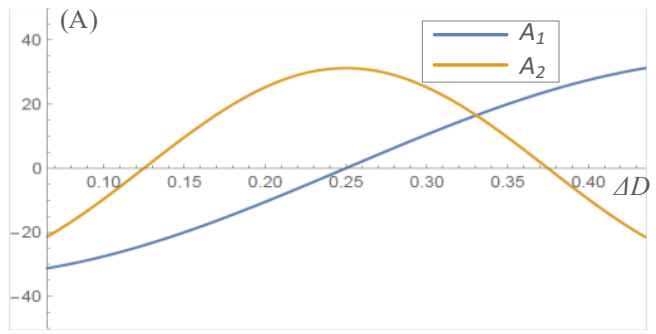

Fig. 10. Magnitudes of the first and second harmonic with $\Delta D$ changing $\left(f_{c}^{[b]}\right.$ and $\left.2 f_{c}^{[b]}\right)$.

The EGW PWM enables active control of the harmonic magnitudes as well as their phase angles. When compared to existing harmonic suppression methods using the conventional modulation technique [18]-[20], it provides a potential of suppressing harmonic of any frequency and magnitude.

\section{PROPOSED HARMONIC SUPPRESSION METHOD}

In this section, an enhanced harmonic suppression method will be proposed using the harmonics generated from the DC- 
DC converter to cancel some specific harmonics from the ACDC converters. We will focus on the $f_{c}-3 f_{0}$ harmonic component from the AC-DC converter as this component is more significant compared to the ones in $f_{c}+3 f_{0}$ and $2 f_{c}$. Without losing generality, similar methods can be developed to suppress other components.

A more detailed system of the hybrid generation centre is shown in Fig. 11. Within such a system, a PMSG supplies power to an HVDC bus through an AC-DC converter. A highvoltage battery supplies power to the HVDC bus $(270 \mathrm{~V})$ via a DC-DC converter. Both converters share the DC-link capacitor. The AC-DC converter and the DC-DC converter are controlled with their local primary controller. A system controller is used for high-level supervision (secondary) control. The systemlevel control is to define power sharing between PMSG and the battery by defining their power references $\left(I_{d c}[g]^{*}\right.$ and $\left.I_{L}{ }^{*}\right)$. The local controllers thus control the converters of the PMSG and the battery to inject the required DC currents into the HVDC bus.

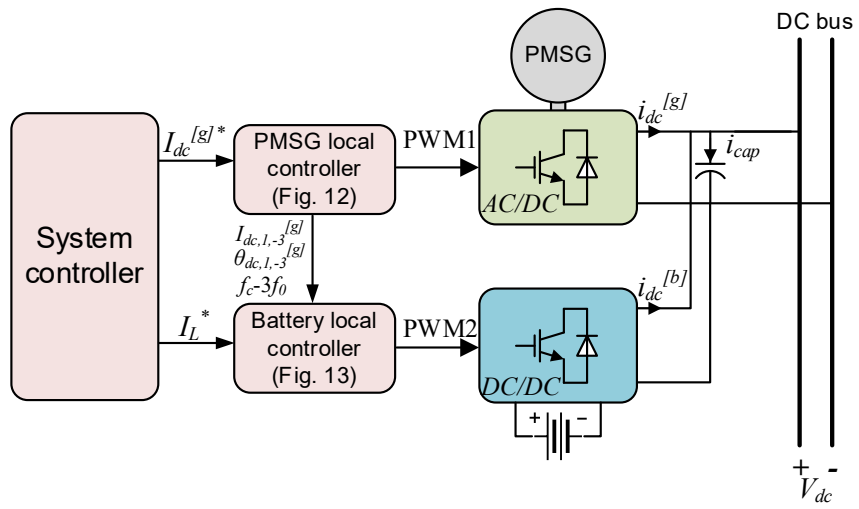

Fig. 11. Control architecture of the hybrid generation system.

The local control diagram of PMSG is shown in Fig. 12. A cascaded control structure has been used, with a current control being the inner loop. A flux-weakening control is applied in the outer control loop. This is due to the fact that in MEA applications, the PMSG is driven by the high-speed shaft of an aircraft engine. The stator output voltage $\sqrt{v_{d}^{2}+v_{q}^{2}}$ is controlled by injecting a negative flux current component $i_{d}$. The output current $i_{d c}$ of the AC-DC converter is also controlled with its reference $i_{\text {ref }}{ }^{g g]}$ given by the system-level controller. With measured currents $i_{d}, i_{q}$, voltage references $v_{d}, v_{q}$, and modulation index $M$, the information of the $f_{c}-3 f_{0}$ harmonic component can be derived, with its magnitude $I_{d c l,-3}{ }^{[g]}$ and its phase angle $\theta_{d c l,-3}[g]$ from (19) and (20). The fundamental frequency $\left(f_{0}\right)$ can be obtained from a machine speed sensor. These features of $f_{c}-3 f_{0}$ component, i.e., magnitude, frequency, and phase angle are then sent to the controller of the DC-DC converter.

The cancellation scheme of the harmonic component of $f_{c}-3 f_{0}$ from the AC-DC converter is essentially based on the fact that two sinusoidal currents of the same magnitude will cancel each other if they are $180^{\circ}$ phase shift to each other. With this fact, we can use a DC-DC converter as an active harmonic injection source to cancel the $f_{c}$ - $3 f_{0}$ harmonic component from the $\mathrm{AC}$ DC converter. To achieve that, the frequency of the carrier signal $\left(f_{c}^{[b]}\right)$ of the DC-DC converter should be set to $f_{c}$ - $3 f_{0}$, i.e.

$$
f_{c}^{[b]}=f_{c}-3 f_{0}
$$

To achieve the phase angle difference of $180^{\circ}$ between the two harmonics, with (20), the phase angle of the EGW PWM carrier signal should be set as

$$
\theta_{c}^{[b]}=\theta_{d c, 1,-3}^{[g]}-\pi=\theta_{c}-2 \operatorname{atan} 2\left(v_{q}, v_{d}\right)-\operatorname{atan} 2\left(i_{q}, i_{d}\right)
$$

where $\theta_{c}^{[b]}$ is the phase angle of the carrier signal of the DC-DC converter. Based on the expression in (39), the phase shift angle of $\pi$ is achieved between components on $f_{c}-3 f_{0}$ from both the PMSG and battery.

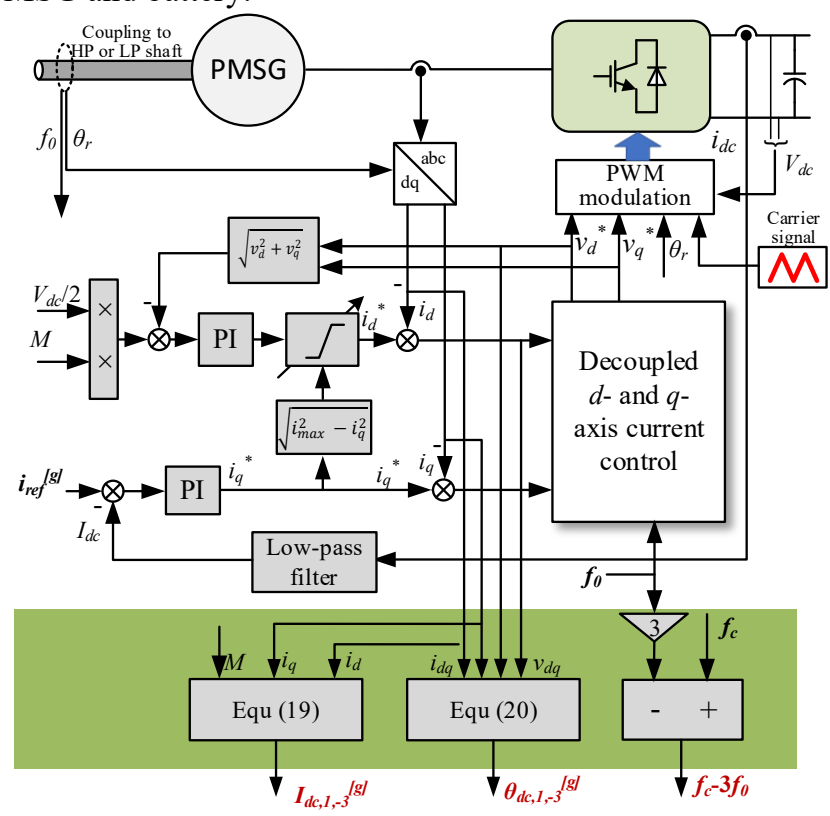

Fig. 12. Control diagram of the PMSG system.

The magnitude of the first order harmonic $\left(f_{c}^{[b]}\right)$ from the DCDC converter is shown in Fig. 10. Combining (19) and (34) will derive the required harmonic amplitude and thus $\triangle D$ in the DCDC converter as

$$
\Delta D=\frac{\cos ^{-1}\left(-\frac{A_{1}^{*} \pi}{4 I_{L} \sin \left(\frac{k \pi D}{2}\right)}\right)}{2 \pi}
$$

where $A_{1} *$ is the required harmonic magnitude and is limited using (34) and (35) as

$$
-\left|\frac{4 \sin \frac{\pi D}{2}}{\pi} I_{L}\right| \leq A_{1}^{*} \leq\left|\frac{4 \sin \frac{\pi D}{2}}{\pi} I_{L}\right|
$$

Therefore, the carrier signal frequency $\left(f_{c}^{[b]}\right)$, magnitude $\left(A_{1}\right)$, offset $\Delta D$ and the phase angle $\theta_{c}^{[b]}$ can be selected based on harmonic information sent from the PMSG controller with (39) and (40), as shown in Fig. 13.

It can be seen from (40) that with a higher inductor current $I_{L}$ (positive or negative), the adjustable range of $A_{l}$ can be wider. Hence, the EGW PWM is more capable of eliminating harmonic when the DC-DC converter operates under higher power.

Meanwhile, when the DC-DC converter works under the charging mode, the inductor current $\left(I_{L}\right)$ becomes a negative 
value. In this case, (39) and (40) are still correct, and thus the proposed method is also effective when the DC-DC converter works under the charging mode.

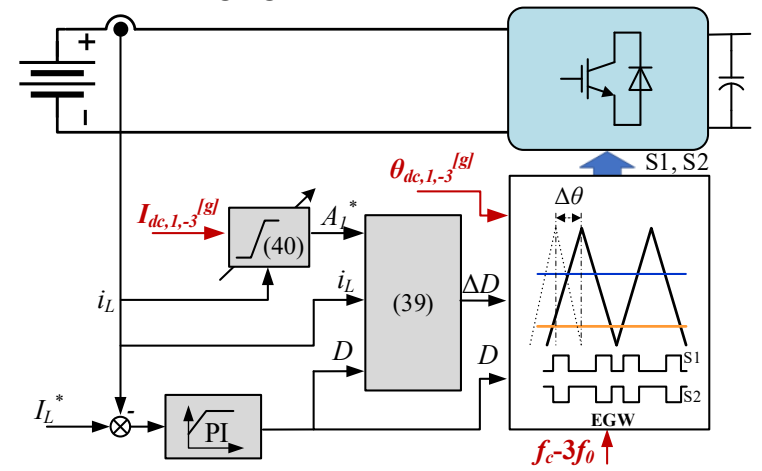

Fig. 13. Control diagram of the battery system.

\section{EXPERIMENT STUDY}

To validate the proposed harmonic cancellation scheme, an experimental rig has been set up as shown in Fig. 14. To simplify the test rig setup, the PMSG is represented by a programmable AC source together with three-phase inductors. A phase-locked loop (PLL) is implemented in the controller to achieve the phase angle of the fundamental AC voltages. The battery is represented by a DC power supply which is connected to the DC-DC converter. Since the harmonic cancellation scheme is related to the AC-DC and the DC-DC converters, using a three-phase AC source and a DC power supply to represent the PMSG and battery will not affect the effectiveness of the proposed harmonics cancellation scheme. For a fixed power, a higher battery voltage results in a lower output/input current. Therefore, a thinner cable can be chosen which benefits the system integration. Hence, the battery voltage is set with a constant voltage output of $200 \mathrm{~V}$. The parameters of the experiment are shown in Table I. The AC fundamental frequency is $50 \mathrm{~Hz}$. The phase-to-phase voltages are $230 \mathrm{~V}$, and the AC-DC converter is controlled with a modulation index of 0.90 , which is to emulate the PMSG operation under the fluxweakening control. The switching frequency of the AC-DC converter, $f_{c}$, is set at $4 \mathrm{kHz}$. The carrier signal frequency for conventional $\mathrm{PWM} f_{c I}[b]$ is set to be $2 f_{c}$, i.e. $8 \mathrm{kHz}$, which is a typical value for such a DC-DC converter. For the EGW PWM method, the carrier frequency $\left(f_{c}^{[b]}\right)$ is set at $f_{c}-3 f_{0}(3.85 \mathrm{kHz})$. Thus, using the EGW PWM method, the switching frequency is $7.7 \mathrm{kHz}$, which is a little lower than that of the conventional PWM. This makes the following comparison still reasonable. In this case, with a lower switching frequency, the efficiency of the DC-DC converter can potentially be improved. However, it will also cause a higher fluctuation on $i_{L}$. Such a trade-off can be studied in the future.

The system is controlled using TI DSP TMS320F28379D, which is embedded with an ePWM module [22]. The EGW PWM of the DC-DC converter can be achieved by properly configuring the PWM actions in the ePWM module according to the counting direction. The extra computation for harmonic suppression is mainly on $f_{c}$-3 $f_{0}$ harmonic estimation and phase shift angle calculation. The computation is tested in the software which is $16 \mu \mathrm{s}$. In the experiment, these calculations are implemented every $20 \mathrm{~ms}$ which is the sample time of DC- link current $\left(i_{d c}^{[g]}\right)$ control. This is much longer than $16 \mu \mathrm{s}$. Thus, the extra computation will not affect system performance.

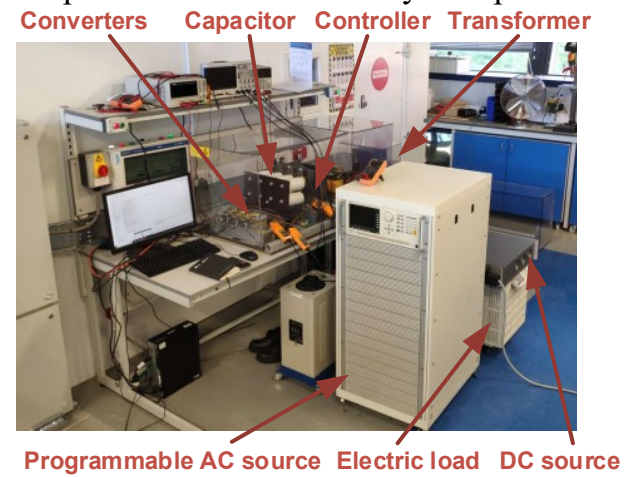

Fig. 14. Experiment setup.

TABLE I. Experimental parameters

\begin{tabular}{lll}
\hline \hline Category & \multicolumn{1}{c}{ Parameters } & Values \\
\hline DC-link & DC bus voltage & $270 \mathrm{~V}$ \\
& DC link capacitance & $4.4 \mathrm{mF}$ \\
& Equivalent series resistance (ESR) & $11 \mathrm{~m} \Omega$ \\
& Equivalent series inductance (ESL) & $8.3 \mathrm{nH}$ \\
\hline AC-DC & Phase inductance & $1 \mathrm{mH}$ \\
converter & Frequencies of AC side $f_{0}$ & $50 \mathrm{~Hz}$ \\
& Voltages of AC side & $230 \mathrm{~V}$ \\
& Switching frequency $f_{c}$ & $4 \mathrm{kHz}$ \\
& Modulation index & 0.90 \\
& $i_{d c}^{[g]}$ control loop frequency & $50 \mathrm{~Hz}$ \\
\hline DC-DC & "Battery" voltage $V_{b a t}$ & $200 \mathrm{~V}$ \\
converter & Inductance & $30 \mathrm{mH}$ \\
& Carrier frequency $f_{c l}^{[b]}$ & $8 \mathrm{kHz}$ (conventional PWM) \\
& Carrier frequency $f_{c}^{[b]}$ & $3.85 \mathrm{kHz}$ (EGW PWM) \\
\hline \hline
\end{tabular}

Fig. 15 shows the DC-bus currents from the AC-DC converter and the DC-DC converter $\left(i_{d c}^{[g]}\right.$ and $\left.i_{d c}^{[b]}\right)$. The current flowing into the capacitor $\left(i_{\text {cap }}\right)$ and its spectrum are also shown in Fig. 15. The output power of the PMSG and the battery are set to $1 \mathrm{~kW}$ and $0.5 \mathrm{~kW}$, respectively. The DC-DC converter is first driven by the conventional PWM with results shown in Fig. 15a and then driven by the proposed EGW PWM scheme with results shown in Fig. 15b. Comparison between the spectrums of $i_{c a p}$ before and after suppression (indicated blue and red respectively) are given in Fig. 15c. The harmonic component of $f_{c}-3 f_{0}$ is suppressed from $2.42 \mathrm{~A}$ to $1.86 \mathrm{~A}(23.1 \%$ reduction). Although with over $20 \%$ reduction, this component is not completely cancelled. This is because the power from the battery (thus current $i_{d c}{ }^{[b]}$ ) is much smaller than that of PMSG (thus current $i_{d c}^{[g]}$ ). In that case, the amplitude of $f_{c}-3 f_{0}$ is even higher than $A_{\text {Imax }}$ which is the maximum the DC-DC converter can generate on this component. The two gate signal pulses in one carrier cycle of the EGW PWM overlap each other. This is equivalent to halving the switching frequency, as shown in Fig. 9. Thus, the switching cycle is increased from $125 \mu \mathrm{s}$ $\left(f_{c l}[b]=8 \mathrm{kHz}\right)$ to $259 \mu \mathrm{s}\left(f_{c}^{[b]}=3.85 \mathrm{kHz}\right)$, as shown in the zoom-in views of Fig. $15 \mathrm{a}$ and $\mathrm{b}$.

However, if we increase the battery power, the harmonic of $f_{c}-3 f_{0}$ can be further suppressed. When the output power of the DC-DC converter is increased to $1 \mathrm{~kW}$, the DC-DC converter should have the capability to fully cancel the $f_{c}-3 f_{0}$ component. Results, in this case, are shown in Fig. 16a and b, and the comparison between the $i_{\text {cap }}$ spectrums (Fig. 16a in blue and 
Fig. 16b in red) is given in Fig. 16c. It can be seen that the harmonic component of $f_{c}-3 f_{0}$ frequency has been suppressed from $2.44 \mathrm{~A}$ to $0.68 \mathrm{~A}$ ( $73.8 \%$ reduction). The error is due to the fact that the magnitude of $f_{c}-3 f_{0}$ component from the AC-DC converter is estimated $I_{d c, 1,-3}$ from (14). Comparing Fig. $16 \mathrm{~b}$ to Fig. 15b, the two gate signal pulses in one carrier cycle do not overlap each other, as shown in the zoom-in view of Fig. $16 \mathrm{~b}$. In this view, $i_{d c}^{[b]}$ counteracts pulses on $i_{d c}^{[g]}$ and the harmonic on the capacitor $\left(i_{c a p}\right)$ can be suppressed.

It is also interesting to notice the change of the $2 f_{c}\left(f_{c}=4 \mathrm{kHz}\right)$ component of $i_{c a p}$. When the DC-DC converter operates with conventional PWM $\left(f_{c l}^{[b]}=8 \mathrm{kHz}\right)$, the current harmonics will be adding to the $2 f_{c}$ component. However, with EGW PWM, the carrier signal has a frequency of $3.85 \mathrm{kHz}$ and there will be no harmonic component at $2 f_{c}$. Therefore, it can be noticed from Fig. 16a and Fig. 16b that the harmonic in $2 f_{c}$ is reduced from $3.48 \mathrm{~A}$ to $1.64 \mathrm{~A}$ (52.9\% reduction).

The proposed method can be extended to other harmonic components on the DC-link, i.e., in $f_{c}+3 f_{0}$. By simply adjusting the carrier frequency (to $f_{c}+3 f_{0}$ ) and the phase angle of the EGW PWM (according to (22)), a suppression of $f_{c}+3 f_{0}$ harmonic can be achieved, as shown in Fig. 17a. The output power of the ACDC and DC-DC converters are $1 \mathrm{~kW}$, and the experimental result without harmonic suppression has been given in Fig. 16a. Comparing Fig. $17 \mathrm{a}$ to Fig. $16 \mathrm{a}$, the harmonic in $f_{c}+3 f_{0}$ is reduced from $1.30 \mathrm{~A}$ to $0.34 \mathrm{~A}(73.8 \%$ reduction), as shown in Fig. 17b.

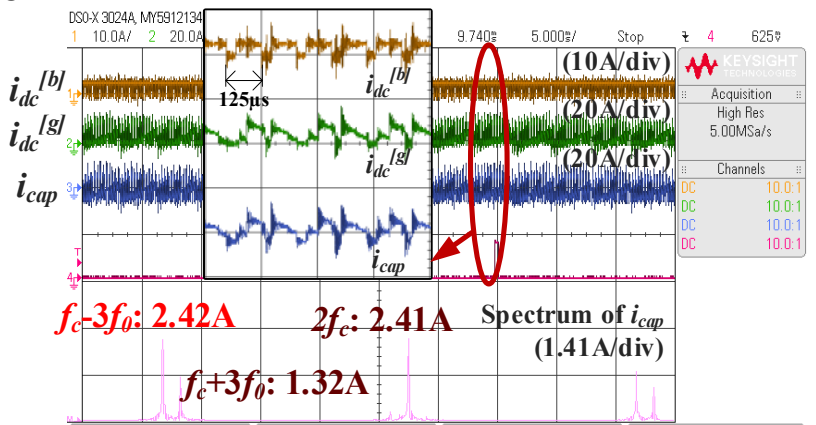

(a)

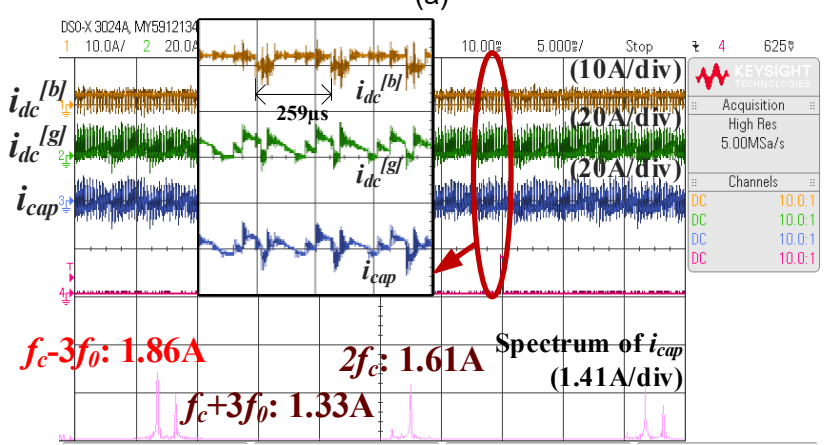

(b)

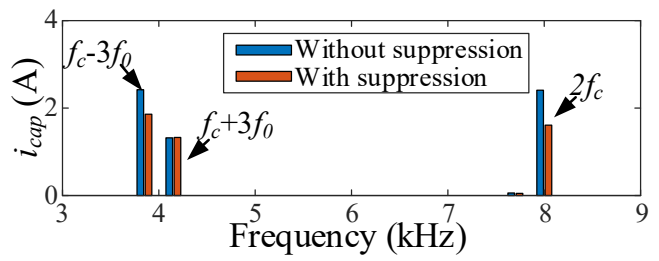

(c)

Fig. 15. Harmonic suppression when $P^{[g]}=1 \mathrm{~kW}, P^{[b]}=0.5 \mathrm{~kW}$. a) Without suppression. b) With EGW suppression. c) Spectrums of $i_{\text {cap. }}$.

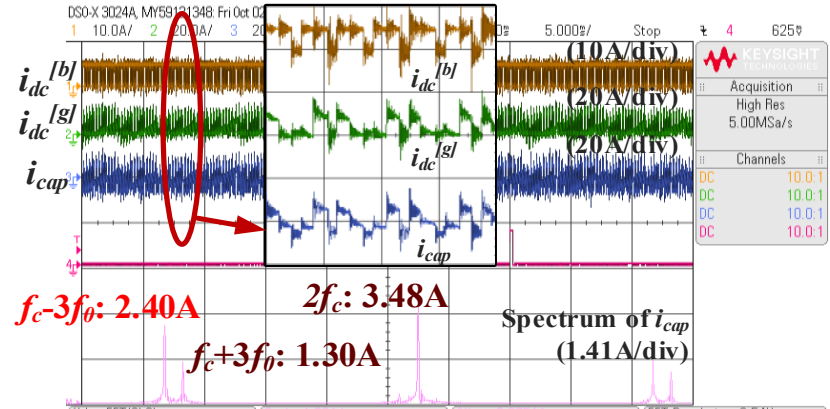

(a)



(b)

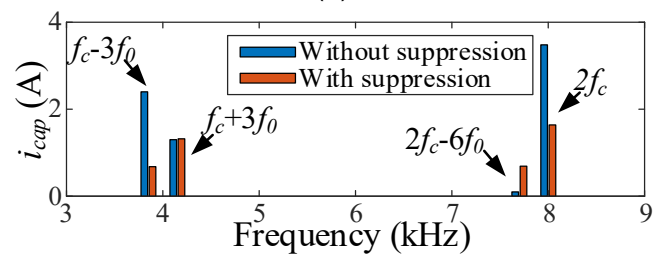

(c)

Fig. 16. Harmonic suppression with EGW suppression when $P^{[g]}=1 \mathrm{~kW}, P^{[b]}=1 \mathrm{~kW}$. a) Without suppression. b) With EGW suppression. c) Spectrums of $i_{\text {cap }}$.

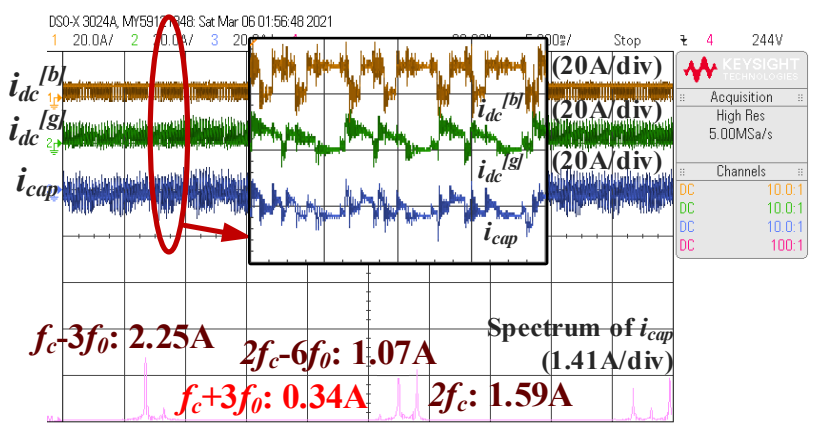

(a)

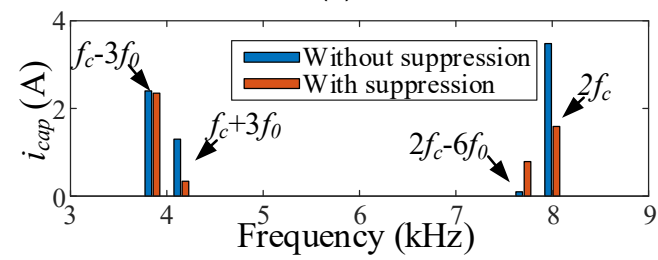

(b)

Fig. 17. Harmonic suppression on $f_{c}+3 f_{0}$ with EGW suppression when $P^{[g]}=1 \mathrm{~kW}, P^{[b]}=1 \mathrm{~kW}$. a) Experimental results. b) Spectrums of $i_{\text {cap }}$ before and after suppression.

The EGW PWM of the DC-DC converter can also operate under buck mode, as shown in Fig. 18. At the beginning of the experiment, as shown in Fig. 18a, only the AC-DC converter supply the DC bus and the output power $\left(P^{[g]}\right)$ is $2 \mathrm{~kW}$. 
Therefore, when the DC-DC converter starts to operate and the output power $\left(P^{[b]}\right)$ is set as $-1 \mathrm{~kW}$, this results in a DC-link voltage $\left(V_{d c}\right)$ drop and recovery, as shown in Fig. 18a. The time scale in Fig. 18a is $200 \mathrm{~ms} /$ div to show the dynamic response of $V_{d c}$. However, such a time scale results in distortion on the DClink current appearance $\left(i_{d c}[g], i_{d c}^{[b]]}\right.$ and $\left.i_{c a p}\right)$, because the switching cycles of the AC-DC and DC-DC converters are $0.25 \mathrm{~ms}$ and $0.26 \mathrm{~ms}$, which is much smaller than $200 \mathrm{~ms}$. Therefore, we provided a zoom-in view near the transient point.

After the system operation is back to the steady state, the battery current is negative. The DC-link current from the DCDC converter $\left(i_{d c}^{[b]}\right)$ is with pulses of negative current $(-5 \mathrm{~A})$. The harmonic component of $f_{c}-3 f_{0}$ is suppressed to $0.42 \mathrm{~A}(79.0 \%$ reduction compared to $f_{c}+3 f_{0}$ component) with the proposed method, as shown in Fig. 18b.

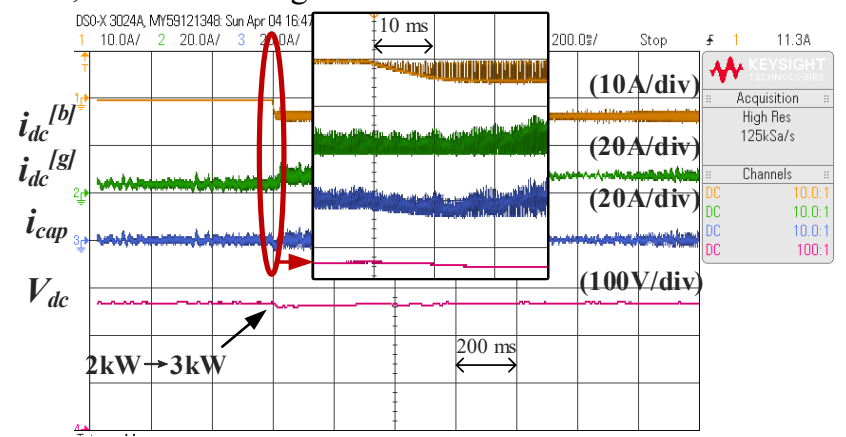

(a)

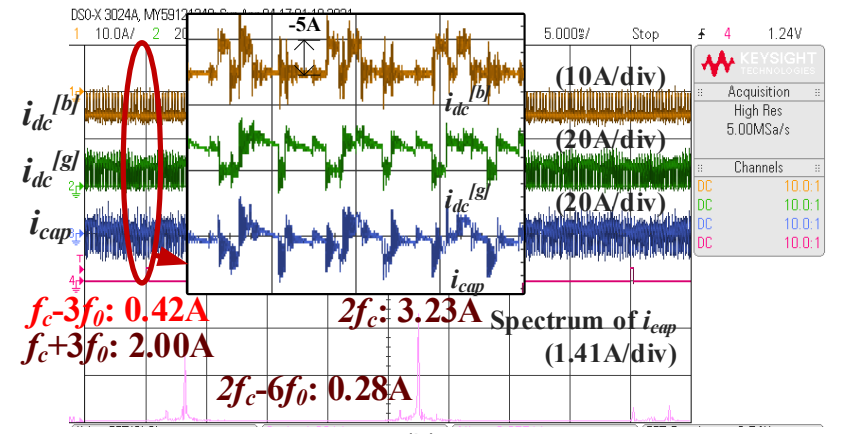

(b)

Fig. 18. Harmonic suppression with EGW suppression when $P^{[g]}=2 \mathrm{~kW}, P^{[b]}=-1 \mathrm{~kW}$. a) Dynamic experiment. b) Steady state.

\section{CONCLUSION}

This paper proposed a new EGW modulation scheme for DCDC converters which enables active damping of harmonics generated from AC-DC converters. This paper focuses on $f_{c}-3 f_{0}$ harmonic cancellation, but similar methods can be used to suppress other components. Experimental results verify the validity of the proposed suppression method. The proposed work is extremely useful to improve power electronic dominated DC grids and can achieve improved power quality with no extra cost. This work will further facilitate some advanced control methods combining with artificial intelligence to achieve system-level power quality optimization, which will be discussed in our future study.

\section{REFERENCES}

[1] P. Wheeler and S. Bozhko, "The more electric aircraft: technology and challenges," IEEE Electrific. Mag., vol. 2, no. 4, pp. 6-12, 2014.
[2] B. Sarlioglu, and C.T. Morris, "More electric aircraft: review, challenges, and opportunities for commercial transport aircraft," IEEE Trans. Transp. Electrif., vol. 1, no. 1, pp. 54-64, Jun. 2015.

[3] F. Gao, S. Bozhko, G. Asher, P. Wheeler, and C. Patel, "An improved voltage compensation approach in a droop-controlled dc power system for the more electric aircraft," IEEE Trans. Transp. Electrif., vol. 31, no. 10, pp. 7369-7383, Dec. 2016.

[4] DO-160E Environmental Conditions and Test Procedures for Airborne Equipment, RTCA Standard, 2004.

[5] MIL-STD-704 Aircraft Electrical Power Characteristics, United States Military Standard, 2004.

[6] H. Wang and F. Blaabjerg, "Reliability of capacitors for dc-link applications in power electronic converters-an overview," IEEE Trans. Ind. Appl., vol. 50, no. 5, pp. 3569-3578, Sept.-Oct. 2014.

[7] Bon-Gwan Gu and Kwanghee Nam, "A dc-link capacitor minimization method through direct capacitor current control," IEEE Trans. Ind. Appl., vol. 42, no. 2, pp. 573-581, March-April 2006.

[8] R. Maheshwari, S. Munk-Nielsen, and K. Lu, "An active damping technique for small DC-link capacitor based drive system," IEEE Trans. Ind. Informat., vol. 9, no. 2, pp. 848-858, May 2013.

[9] H. Tian and Y. Li, "Virtual resistor based second-order ripple sharing control for distributed bidirectional DC-DC converters in hybrid AC-DC microgrid," IEEE Trans. Power Electron., vol. 36, no. 2, pp. 2258-2269, Feb. 2021.

[10] N. Zhao, G. Wang, D. Xu, L. Zhu, G. Zhang and J. Huo, "Inverter power control based on DC-link voltage regulation for IPMSM drives without electrolytic capacitors," IEEE Trans. Power Electron., vol. 33, no. 1, pp. 558-571, Jan. 2018

[11] M. Mellincovsky, V. Yuhimenko, M. M. Peretz and A. Kuperman, "Analysis and control of direct voltage regulated active DC-link capacitance reduction circuit," IEEE Trans. Power Electron., vol. 33, no. 7, pp. 6318-6332, July 2018.

[12] W. Liu, K. Wang, H. S. Chung and S. T. Chuang, "Modeling and design of series voltage compensator for reduction of DC-link capacitance in grid-tie solar inverter," IEEE Trans. Power Electron., vol. 30, no. 5, pp. 2534-2548, May 2015.

[13] C. Ren, X. Han, L. Wang, Y. Yang, W. Qin and P. Wang, "Highperformance three-phase pwm converter with a reduced DC-link capacitor under unbalanced AC voltage conditions," IEEE Trans. Ind. Electron., vol. 65, no. 2, pp. 1041-1050, Feb. 2018.

[14] S. Li, A. T. L. Lee, S. Tan and S. Y. R. Hui, "Plug-and-play voltage ripple mitigator for DC links in hybrid AC-DC power grids with local busvoltage control," IEEE Trans. Ind. Electron., vol. 65, no. 1, pp. 687-698, Jan. 2018

[15] C. Wang, T. Yang, P. Kulsangcharoen and S. Bozhko, "An enhanced second carrier harmonic cancellation technique for dual-channel enhanced power generation centre applications in more-electric aircraft," IEEE Trans. Ind. Electron., vol. 68, no. 7, pp. 5683-5692, July 2021.

[16] L. Shen, S. Bozhko, G. Asher, C. Patel and P. Wheeler, "Active dc-link capacitor harmonic current reduction in two-level back-to-back converter," IEEE Trans. Power Electron., vol. 31, no. 10, pp. 6947-6954, Oct. 2016.

[17] D. G. Holmes and T. Lipo, Pulsewidth Modulation for Power Converters. 568 New York, NY, USA: Wiley, 2003.

[18] F. D. Kieferndorf, M. Forster and T. A. Lipo, "Reduction of DC-bus capacitor ripple current with PAM/PWM converter," IEEE Trans. Ind. Appl., vol. 40, no. 2, pp. 607-614, March-April 2004.

[19] X. Lu and F. Z. Peng, "Theoretical analysis of DC link capacitor current ripple reduction in the HEV DC-DC converter and inverter system using a carrier modulation method," 2012 IEEE Energy Conversion Congress and Exposition (ECCE), Raleigh, NC, 2012, pp. 2833-2839.

[20] K. Choi, S. Kim, S. Jung and R. Kim, "Generalized switching modification method using carrier shift for DC-link capacitor rms current reduction in real-time implementation," IEEE Trans. Ind. Electron., vol. 66, no. 8, pp. 5992-6001, Aug. 2019.

[21] S. Bozhko, M. Rashed, C. I. Hill, S. S. Yeoh and T. Yang, "Fluxweakening control of electric starter-generator based on permanentmagnet machine," IEEE Trans. Transp. Electrif., vol. 3, no. 4, pp. 864877, Dec. 2017.

[22] TMS320F2837xD Dual-Core Microcontrollers Technical Reference Manual.https://www.ti.com/product/TMS320F28379D?keyMatch=2837 9\&tisearch $=$ Search-EN-everything\&usecase $=$ GPN .

[23] Petr Frgal, "Average Current Mode Interleaved PFC Control," https://www.nxp.com/docs/en/application-note/AN5257.pdf. 


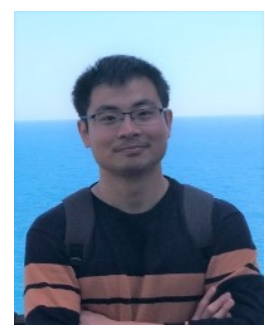

Cheng Wang was born in Jiangsu, China. He received the B.Eng. and M.Sc. degrees in electrical engineering from Nanjing University of Aeronautics and Astronautics, Nanjing, China, in 2013 and 2016, respectively. Since 2017, he is currently working toward the Ph.D. degree in electrical and electronic engineering with the Power Electronics, Machines, and Control Group, University of Nottingham, Nottingham, U.K.

His research interests include control and power quality improvement in area of electric DC power systems.

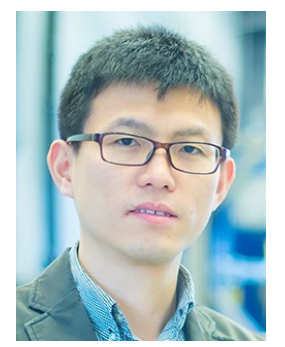

Tao Yang (M'16-SM'20) received his MEng Degree from Shanghai Jiao Tong University, China in 2008 and his Ph.D. degree in electrical engineering from the University of Nottingham, UK in 2013.

Since 2013, he has been a Researcher with Power Electronics, Machines and Control Group, University of Nottingham, where he became an Assistant Professor in 2016, and an Associate Professor in 2019. His research interests include high-speed electric motor drive control, power electronic conversion, electrical system design and optimization for more electric/hybrid/all-electric aircraft applications. His $\mathrm{PhD}$ research within EU Clean Sky on "Modelling electrical power system for more-electric aircraft applications" has resulted in him winning the inaugural "Clean Sky Best PhD Award" in 2016.

Dr. Yang is an Associate Editor for the IEEE TRANSACTIONS ON TRANSPORTATION ELECTRIFICATION and Chinese Journal of Aeronautics.

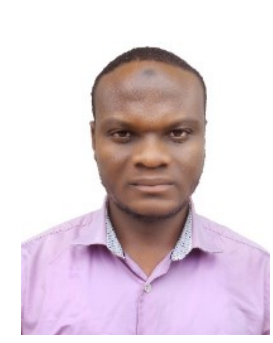

Habibu Hussaini received his B.Eng. degree in Electrical and Computer Engineering from the Federal University of Technology, Minna, Nigeria in 2010. He obtained his MSc in Energy and Sustainability with Electrical Power Engineering from the University of Southampton, United Kingdom in 2015. He is currently studying for his Ph.D. in Electrical and Electronics Engineering at the University of Nottingham, United Kingdom.

His research interests include aircraft electrical power systems, artificial intelligence, power electronics and control.

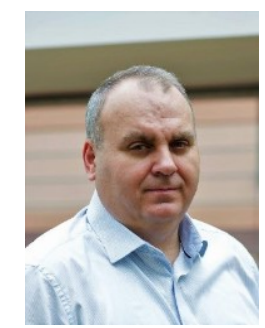

Serhiy Bozhko (M'96-SM'18) received his M.Sc. and Ph.D. degrees in electromechanical systems from the National Technical University of Ukraine, Kyiv City, Ukraine, in 1987 and 1994, respectively.

Since 2000, he has been with the Power Electronics, Machines and Controls Research Group of the University of Nottingham, United Kingdom, where currently he is Professor of Aircraft Electric Power Systems and Director of the Institute for Aerospace Technology. He is leading several EU- and industry funded projects in the area of aircraft electric power systems, including power generation, distribution and conversion, power quality, control and stability issues, power management and optimization, as well as advanced modeling and simulations methods. 